\title{
Transcatheter mitral valve regurgitation treatment: State of the art and a glimpse to the future
}

\author{
Luca Testa, MD, PhD, ${ }^{a}$ Azeem Latib, MD, ${ }^{\mathrm{b}}$ Rocco A. Montone, MD, ${ }^{\mathrm{a}}$ and Francesco Bedogni, MD
}

\section{ABSTRACT}

Since the first transcatheter heart valve implantation in the pulmonary position in 2000 and in the aortic position in 2002, a large number of transcatheter heart valves have reached the clinical arena and thousands of high-risk patients have been treated successfully, in particular those with severe aortic stenosis. In contrast, the experience of transcatheter mitral valve repair or implantation started relatively more recently, and only a few devices are available at the moment. The aim of this review is to describe the different percutaneous systems for the treatment of mitral regurgitation. (J Thorac Cardiovasc Surg 2016;152:319-27)

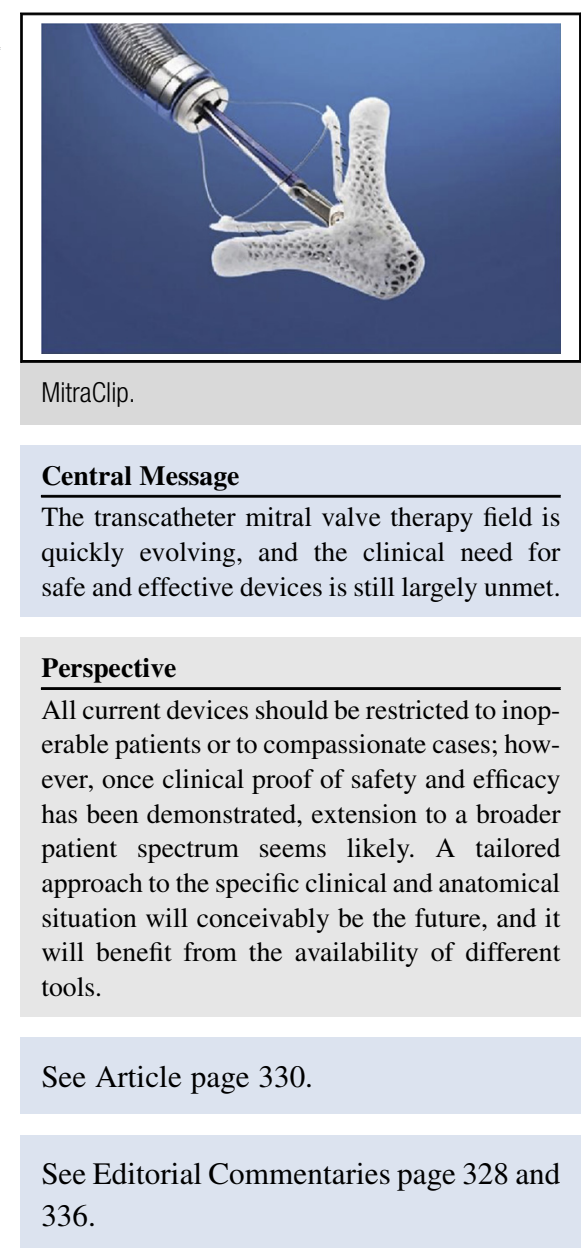

The incidence of mitral regurgitation (MR) in the general population of Western countries and in individuals older than 75 years of age is almost $1.7 \%$ and $10 \%$, respectively, ${ }^{1}$ and surgery is currently the gold standard for the treatment of severe MR, regardless of the adoption of minimally invasive techniques. The presence of severe comorbidities, however, precludes surgical treatment in up to $50 \%$ of patients

\footnotetext{
From the ${ }^{\mathrm{a}}$ Department of Cardiology, IRCCS Pol. S. Donato, S. Donato Milanese; and ${ }^{\mathrm{b}} \mathrm{S}$. Raffaele Scientific Institute, Emo Columbus, Milan, Italy.

Received for publication March 14, 2016; revisions received April 1, 2016; accepted for publication April 19, 2016; available ahead of print May 26, 2016.

Address for reprints: Luca Testa, MD, PhD, IRCCS Pol. S. Donato, S. Donato Milanese, Milan, Italy (E-mail: luctes@gmail.com). $0022-5223 / \$ 36.00$

Copyright (c) 2016 by The American Association for Thoracic Surgery http://dx.doi.org/10.1016/j.jtcvs.2016.04.055
}

with severe MR. ${ }^{2}$ Indeed, transcatheter mitral valve repair (MVR) may be an alternative therapeutic option, ${ }^{3}$ as proven by the encouraging results of the edge-to-edge technique with the MitraClip system (Abbott Vascular Inc, Menlo Park, Calif).

Of note, several MVR technologies are being developed (Tables 1 and 2), although successful MVR with

Scanning this QR code will take you supplemental videos for the article.

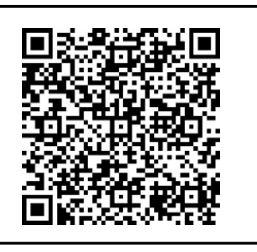



Abbreviations and Acronyms
$\mathrm{AML}=$ anterior mitral leaflet
$\mathrm{CE}=$ Conformité Européenne
$\mathrm{Fr} \quad=$ French
$\mathrm{LV}=$ left ventricle/ventricular
LVOT $=$ left ventricular outflow tract
$\mathrm{MR}=$ mitral regurgitation
$\mathrm{MV}=$ mitral valve
MVI $=$ mitral valve implantation
MVR $=\underset{\text { mitral valve repair/reconstruction/ }}{\text { replacement }}$
PML $=$ posterior mitral leaflet

transcatheter aortic valve implantation prostheses have been performed in patients with degenerated surgical bioprostheses or with recurrent MR after annuloplasty. ${ }^{4}$

\section{MITRAL VALVE REPAIR}

Current transcatheter mitral valve repair technologies are discussed in this section (Figure 1).

\section{Leaflet Plication}

As first described by Alfieri et al, ${ }^{5}$ the leaflet plication technique consists of creating a "double orifice" by bringing the anterior mitral (AML) and posterior mitral leaflet (PML) together, thus improving the coaptation and reducing the regurgitant orifice. As a result, leaflet coaptation is re-established and MR minimized.

The MitraClip system consists of a polyester-covered cobalt-chromium clip. (See Videos 1 and 2 for a case of degenerative MR; see Videos 3 and 4 for a case of ischemic MR. Both cases have been successfully treated with Mitraclip system.) It is introduced by a 24-French (Fr) delivery catheter via the femoral vein into the right atrium and, after transseptal puncture, advanced into the left atrium. Under 2-dimensional and 3-dimensional echocardiographic and fluoroscopic guidance, the clip is positioned above the mitral valve (MV), opened, and advanced into the left ventricle. Subsequently, it is retracted so that the free edges of AML and PML are loaded onto the clip at the origin of the regurgitant jet; closure of the clip results in a "double-orifice" MV.

The MitraClip system initially was evaluated in the EVEREST-I (Endovascular Valve Edge-to-Edge Repair Study ${ }^{6}$ and EVEREST-II trials. ${ }^{7}$ The EVEREST-II trial ${ }^{7}$ allocated 279 patients in a 2:1 ratio to MitraClip or surgery. The combined safety endpoint (incidence of severe adverse events to 30 days) was reached in $15 \%$ of interventional and $48 \%$ of surgical patients $(P<.001)$, even though transfusion of $\geq 2$ units represented the majority of adverse events. After transfusion was excluded, no significant difference in safety was seen $(P=.23)$. Of note, $20 \%$ of MitraClip patients underwent secondary MV surgery. In $46 \%$ of interventional patients, MR was Grade $2+$ or greater at 12 months. The efficacy of the MitraClip device currently is being evaluated in randomized controlled trials against best medical therapy in the COAPT (Clinical Outcomes Assessment of the MitraClip Percutaneous Therapy) $)^{8}$ and RESHAPE-HF (MitraClip Device in Heart Failure Patients with Clinically Significant Functional Mitral Regurgitation) $)^{9}$ trials.

A second device for leaflet plication is undergoing preclinical testing: The Mitraflex system (TransCardiac Therapeutics, Atlanta, Ga) combines the possibility of deploying a clip for leaflet plication and implanting an artificial chord during the same procedure via the transapical route.

\section{Leaflet Coaptation Enhancement}

The MitraSpacer device (Cardiosolutions, Stoughton, Mass), which currently is undergoing a phase 1 trial, is a balloon-shaped spacer that is delivered percutaneously via the transseptal route and made of a polyurethane-silicone polymer. It is advanced into the mitral orifice and anchored to the left ventricular (LV) apex. The device provides a surface that the leaflets can coapt against, thus reducing MR.

Another device, the Mitralix, is a spiral-shape device that is inserted into the LV to pull the chordae together. This device is at a very early stage of its development.

\section{Leaflet Ablation}

Through radiofrequency energy, fibrosis and reduced motion of the leaflets are caused. To date the feasibility of this principle was proven in animal models with the ThermoCool irrigation ablation electrode (Biosense Webster, Inc, Diamond Bar, Calif).

\section{THE ANNULOPLASTY APPROACH Indirect Annuloplasty}

The CARILLON Mitral Contour System (Cardiac Dimensions, Inc, Kirkland, Wash) consists of a central nitinol element that connects a distal anchor and proximal anchor. After transjugular access, the anchoring portions are placed in the vena cordis magna and proximal cardiac sinus. By foreshortening the central element, the device remodels the posterior periannular tissue.

In the prospective, multicenter AMADEUS trial (Carillon Mitral Annuloplasty Device European Union Study), ${ }^{10}$ implantation of the device was successful in 30 of 48 patients $(63 \%)$. The device has Conformité Européenne (CE) mark and currently is being implanted commercially as well as being evaluated in a few prospective studies.

The MONARC System (Edwards Lifesciences, Irvine, Calif) has self-expanding distal and proximal anchoring segments connected by a central spring. After implantation, the central portion foreshortens and reduces septolateral 
TABLE 1. Transcatheter mitral valve repair technology under development

\begin{tabular}{|c|c|c|c|}
\hline Device name & Therapy type & Description & International status \\
\hline MitraClip (Abbot Vascular) & Edge-to-edge repair & $\begin{array}{l}\text { - Percutaneous mitral repair based on } \\
\text { Alfieri edge-to-edge surgical approach, } \\
\text { designed for both degenerative and } \\
\text { FMR. } \\
\text { - Features a tiny V-shaped clip. } \\
\text { - Indication requested for FDA approval } \\
\text { is significant symptomatic DMR in } \\
\text { presence of prohibitive risk for mitral } \\
\text { valve surgery }\end{array}$ & $\begin{array}{l}\text { CE Mark approval gained } \\
\text { FDA approved }\end{array}$ \\
\hline NeoChord (NeoChord DS1000) & Chordal repair & $\begin{array}{l}\text { - Instrumentation used to enable beating } \\
\text { heart, transapical approach, mitral } \\
\text { valve repair by artificial chordae } \\
\text { implantation } \\
\text { - Designed for leaflet prolapse }\end{array}$ & CE Mark approval gained \\
\hline V-Chordal-Off Pump (Valtech) & Chordal repair & $\begin{array}{l}\text { - Sutureless implantation of neochordae } \\
\text { on the leaflets under direct surgical } \\
\text { exposure } \\
\text { - Off-pump, the chordal length can be } \\
\text { adjusted under live echo guidance, on } \\
\text { beating heart }\end{array}$ & First-in-human study complete \\
\hline CARILLON (Cardiac Dimensions) & Indirect annuloplasty & $\begin{array}{l}\text { - Implantable mitral annular constraint } \\
\text { device percutaneously placed into the } \\
\text { coronary sinus and great cardiac vein } \\
\text { - Constructed of nitinol wire with distal } \\
\text { and proximal anchors connected by an } \\
\text { intervening cable } \\
\text { - Designed specifically for heart failure } \\
\text { patients with significant MR due to } \\
\text { mitral annular enlargement }\end{array}$ & $\begin{array}{l}\text { CE Mark approval gained } \\
\text { IDE submitted for pivotal study }\end{array}$ \\
\hline MVRx ARTO System & Indirect annuloplasty & $\begin{array}{l}\text { - Transvenous delivery of } 2 \text { anchors: } 1 \text { to } \\
\text { the atrial septum and the other to the } \\
\text { coronary sinus; } \\
\text { - Acutely removable and acts by } \\
\text { reducing the anteroposterior diameter } \\
\text { of the mitral annulus } \\
\text { - Designed specifically for heart failure } \\
\text { patients with significant MR due to } \\
\text { mitral annular enlargement }\end{array}$ & \\
\hline GDS Accucinch (GDS) & Direct annuloplasty & $\begin{array}{l}\text { - Catheter-based delivery of a } \\
\text { subvalvular left ventricular reshaping } \\
\text { (ventriculoplasty) system designed to } \\
\text { reshape and resize the left ventricular } \\
\text { base } \\
\text { - Re-establish native mitral valve } \\
\text { geometry while preserving native } \\
\text { leaflet function and restore leaflet } \\
\text { coaptation }\end{array}$ & International feasibility trial underway \\
\hline Mitralign Bident (Mitralign) & Direct annuloplasty & $\begin{array}{l}\text { - Transcatheter annuloplasty for mitral } \\
\text { repair } \\
\text { - Involves delivery of polyester pledgets } \\
\text { via LV through posterior mitral } \\
\text { annulus } \\
\text { - Pledgets are plicated and locked } \\
\text { directly on the annulus }\end{array}$ & $\begin{array}{l}\text { CE Mark trial completed } \\
\text { US feasibility trial planned }\end{array}$ \\
\hline
\end{tabular}


TABLE 1. Continued

\begin{tabular}{|c|c|c|c|}
\hline Device name & Therapy type & Description & International status \\
\hline Cardioband TF (Valtech) & Direct annuloplasty & $\begin{array}{l}\text { An adjustable, sutureless posterior } \\
\text { annuloplasty band implanted trough } \\
\text { transfemoral transeptal route } \\
\text { - Designed to reduce the septolateral } \\
\text { annular diameter }\end{array}$ & CE Mark trial underway \\
\hline Millipede Ring (Millipede) & Direct annuloplasty & $\begin{array}{l}\text { Nitinol ring designed for tricuspid or } \\
\text { mitral valve repair }\end{array}$ & Preclinicals underway \\
\hline Cardica Mitral Repair (Cardica) & Edge-to-edge repair & $\begin{array}{l}\text { Catheter-based treatment for MR } \\
\text { featuring a clip that holds together } \\
\text { the leaflets of the mitral valve }\end{array}$ & Intellectual property developed \\
\hline MISTRAL (Mitralix) & Chordal repair & $\begin{array}{l}\text { - Transseptally delivered (12-Fr } \\
\text { catheter) implant (3D nitinol spiral- } \\
\text { shaped atraumatic wire) for mitral } \\
\text { valve repair via chord grasping } \\
\text { - This is Mitralix's first product }\end{array}$ & Preclinicals underway \\
\hline V-Chordal-Transfemoral (Valtech) & Chordal repair & $\begin{array}{l}\text { Transfemoral chord repair performed } \\
\text { via transfemoral approach that is } \\
\text { off-pump on a beating heart }\end{array}$ & Preclinicals underway \\
\hline Kardium MR (Kardium) & Direct annuloplasty & $\begin{array}{l}\text { Kardium is developing a percutaneous } \\
\text { device for treating mitral valve } \\
\text { regurgitation }\end{array}$ & Intellectual property developed \\
\hline PS3 (MVRx) & Annuloplasty & $\begin{array}{l}\text { Direct leveraged transatrial shortening of } \\
\text { the septolateral dimension of the mitral } \\
\text { valve by providing two anchor points } \\
\text { that are tensioned together }\end{array}$ & $\begin{array}{l}\text { First-in-human study } \\
\text { underway }\end{array}$ \\
\hline MitraFlex (TransCardiac) & Edge-to-edge & $\begin{array}{l}\text { Instruments for minimally invasive } \\
\text { transapical mitral valve repairs }\end{array}$ & Preclinicals underway \\
\hline ValCare MV Repair (ValCare) & Direct annuloplasty & $\begin{array}{l}\text { A rigid, D-shaped annuloplasty ring that } \\
\text { is delivered in a transcatheter approach } \\
\text { to reduce MR and stabilize the mitral } \\
\text { annulus for functional and } \\
\text { degenerative MR }\end{array}$ & Preclinicals underway \\
\hline $\begin{array}{l}\text { Mitra-Spacer-Transapical } \\
\quad \text { (Cardiosolutions) }\end{array}$ & Enhanced coaptation & $\begin{array}{l}\text { - Catheter-based mitral valve spacer to } \\
\text { reduce MR improving leaflet } \\
\text { coaptation } \\
\text { - Implanted through transapical } \\
\text { approach }\end{array}$ & $\begin{array}{l}\text { First-in-human study } \\
\text { underway }\end{array}$ \\
\hline Mitralix & Enhanced coaptation & $\begin{array}{l}\text { Spiral-shaped device inserted into the } \\
\text { LV to pull the chordae together }\end{array}$ & Animal lab underway \\
\hline
\end{tabular}

$\overline{F M R}$, Functional mitral regurgitation; FDA, Food and Drug Administration; $D M R$, degenerative mitral regurgitation; $C E$, Conformité Européenne; $M R$, mitral regurgitation; $I D E$, Investigational Device Exemption; $M V R x$, mitral valve therapy; $G D S$, guided delivery system; $L V$, left ventricle; $U S$, United States; $T F$, transfemoral; $F r$, French.

circumference of the annulus. In the multicenter EVOLUTION-I (Clinical Evaluation of the Edwards Lifesciences Percutaneous Mitral Annuloplasty System for The Treatment of Mitral Regurgitation) trial, ${ }^{11}$ procedural success was $82 \%$. In $30 \%$, compression of coronary arteries was noted. In light of these results, the device is no longer available.

Currently, devices that add a second traction force on the left atrium or right atrium, such as the device by St. Jude Medical (Minneapolis, Minn) that implants helical screws into the myocardium at the posteromedial mitral annulus, proved feasible in the animal model. ${ }^{12}$
A clear limitation of the indirect annuloplasty approach relies on the progressive distance between the coronary sinus and the mitral plane after the enlargement of the atrium, the variable spatial relationship between the coronary sinus and mitral annulus, and the risk of circumflex artery compression. Thus, the annuloplasty approach will probably be ideal for smaller atriums only. ${ }^{13}$

The MVRx ARTO System (Septal Sinus Shortening) basically delivers 2 anchors transvenously: one to the atrial septum and the other to the coronary sinus. It can be removed quickly and acts by reducing the anteroposterior diameter of the mitral annulus. ${ }^{14}$ 
TABLE 2. Transcatheter mitral valve implantation technology under development

\begin{tabular}{|c|c|c|}
\hline Device name & Description & Status \\
\hline FORTIS (Edwards Lifesciences) & $\begin{array}{l}\text { - Mitral valve replacement technology designed to minimize paravalvular leak } \\
\text { - Initial version being studied in first-in-human has a transapical delivery system }\end{array}$ & First-in-human study underway \\
\hline Tiara (Neovasc) & $\begin{array}{l}\text { - Self-expanding bovine pericardial, D-shaped trileaflet mitral valve implanted } \\
\text { using a transapical delivery system } \\
\text { - It is anchored to the mitral annulus } \\
\text { - A transfemoral delivery system is also in development }\end{array}$ & First-in-human study underway \\
\hline TMVI-TA (CardiAQ) & $\begin{array}{l}\text { Self-positioning, self-anchoring, and self-conforming system for transcatheter } \\
\text { mitral valve implantation through transapical approach }\end{array}$ & First-in-human study completed \\
\hline TMVI-TF (CardiAQ) & $\begin{array}{l}\text { - Self-positioning, self-anchoring, and self-conforming system for transcatheter } \\
\text { mitral valve implantation } \\
\text { - Second-generation device has been developed; this profile covers transfemoral } \\
\text { version }\end{array}$ & First-in-human study completed \\
\hline Caisson TMVR (Caisson) & Mitral valve replacement system with a transfemoral delivery system & Preclinicals underway \\
\hline MitraCath (Emory University) & $\begin{array}{l}\text { Technology that enables the placement of a stent-mounted bioprosthetic heart valve } \\
\text { in the mitral position }\end{array}$ & In development \\
\hline $\begin{array}{l}\text { HighLife Mitral Valve } \\
\text { Replacement (HighLife) }\end{array}$ & $\begin{array}{l}\text { Percutaneous mitral valve replacement technology with a transatrial delivery } \\
\text { system }\end{array}$ & Preclinicals underway \\
\hline Medtronic TMVR (Medtronic) & $\begin{array}{l}\text { - Self-expanding nitinol scaffold and a bovine pericardium valve with three cusps } \\
\text { - Designed for fixation with the native mitral annulus }\end{array}$ & Preclinicals underway \\
\hline MitrAssist Valve (MitrAssist) & $\begin{array}{l}\text { - A mitral valve that fits into the existing mitral valve } \\
\text { - Delivered through a small-diameter catheter } \\
\text { - For all forms of mitral regurgitation }\end{array}$ & Preclinicals underway \\
\hline Navigate TMVR & $\begin{array}{l}\text { - Self-expandable mitral valve replacement device featuring a nitinol stent and } \\
\text { dehydrated tissue for treatment of functional mitral regurgitation } \\
\text { - Transatrial, transapical, and transseptal versions are also in development }\end{array}$ & Clinical implants have occurred \\
\hline $\begin{array}{l}\text { Tendyne/Lutter TMVR } \\
\text { (Tendyne) }\end{array}$ & $\begin{array}{l}\text { - Self-expanding, transapical approach to mitral valve replacement } \\
\text { - System involves neochords with left ventricular apical tethering for fixation }\end{array}$ & First-in-human study underway \\
\hline Cardiovalve (Valtech) & $\begin{array}{l}\text { Mitral valve replacement system that can be delivered using a transfemoral delivery } \\
\text { system in a 2-step replacement procedure }\end{array}$ & Preclinicals underway \\
\hline
\end{tabular}

TMVI-TA, Transcatheter mitral valve implantation-transapical; TMVI-TF, transcatheter mitral valve implantation-transfemoral; $T M V R$, transcatheter mitral valve replacement.

\section{Direct Annuloplasty}

The Valtech Cardioband (Valtech Cardio, Or Yehuda, Israel) is delivered via a transvenous, transseptal route and uses nitinol screws inserted into the atrial aspect of the mitral annulus in a commissure-to-commissure fashion. In a second step, the implant is cinched to reduce annular dimensions and MR. Experimental and early clinical data are available. ${ }^{15,16}$

The Mitralign Percutaneous Annuloplasty System (Mitralign Inc, Tewksbury, Mass) delivers a pair of pledgets on the mitral annulus via the transventricular route. The pledgets are plicated and locked on the ventricular side. ${ }^{17}$

The QuantumCor device (QuantumCor, Lake Forest, Calif) has been tested in animal models and works with heat energy applied to the mitral annulus, causing constriction. $^{18}$

\section{THE CHORDAL APPROACH}

A novel device for transapical implantation of neochordae has been evaluated clinically and recently received the $\mathrm{CE}$ mark (NeoChord DS1000; NeoChord Inc, Minneapolis, Minn). The delivery catheter is inserted via standard transapical access into the left ventricle. Under 2-dimensional and 3-dimensional echocardiographic guidance, the free edge of the prolapsing segment of PML or AML is grasped. Color-sensitive fiberoptics confirm grasping of sufficient leaflet tissue. Neochordae subsequently are externalized through the LV apex and fixed at the correct length under echo guidance. Clinical feasibility and safety have recently been demonstrated in the Transapical Artificial Chordae Tendineae (TACT) trial and further evaluation is being pursued in a postmarket registry at present. ${ }^{19}$

\section{The LV Remodeling Approach}

In patients with ischemic or cardiomyopathy-induced functional MR, a reduction of LV dimensions can lead to a reduction of MR. The idea is to decrease the septolateral annular distance and bring the LV papillary muscles to the leaflets by reducing the anteroposterior dimension of the LV.

Currently, there is one device that follows the concept of reducing the anteroposterior dimension of the $\mathrm{LV}$ by reducing the septolateral annular distance: the MardilBACE (Mardil, Inc, Morrisville, NC), which has been tested 

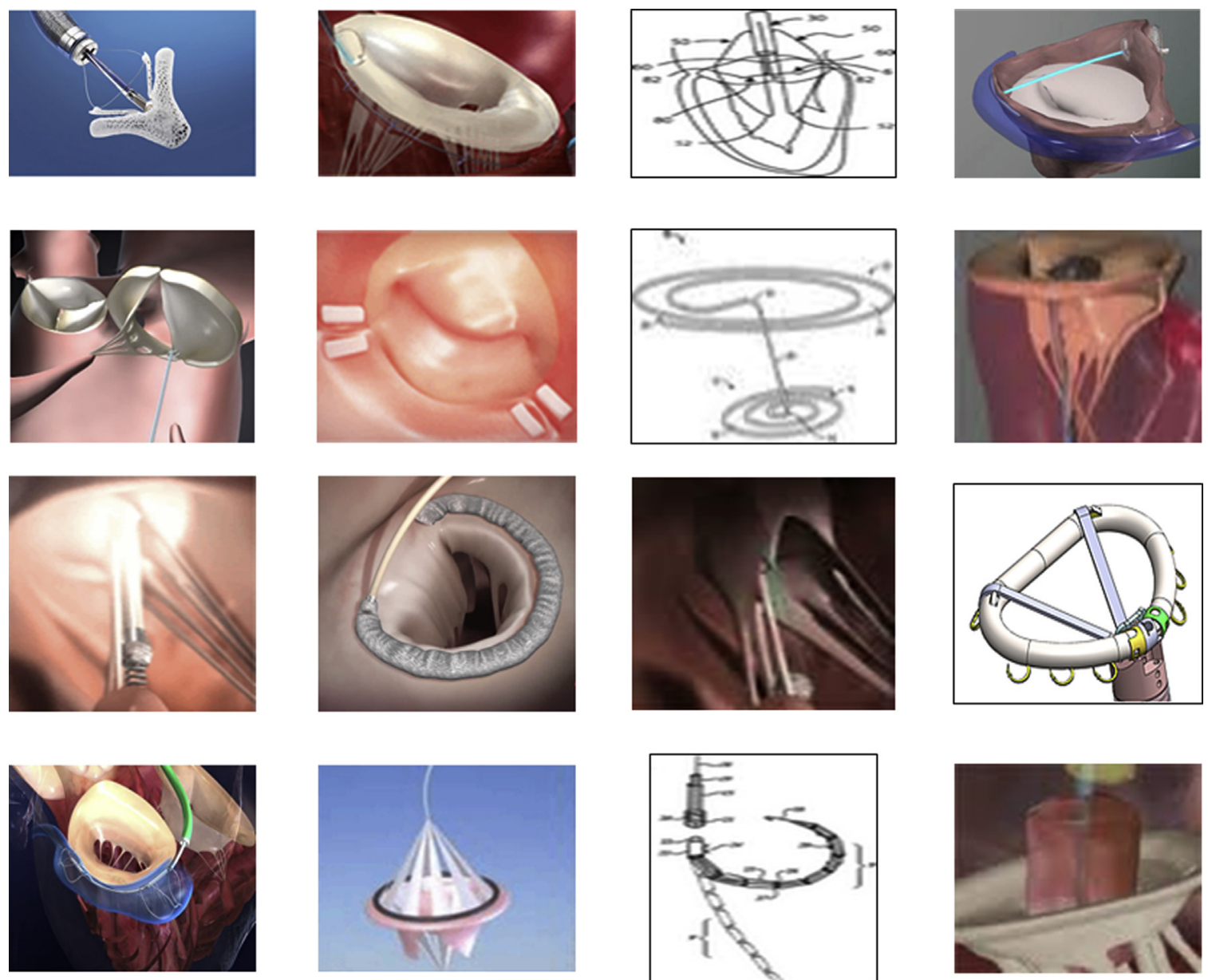

FIGURE 1. Transcatheter mitral valve repair technologies. First column from top to bottom: MitraClip (Abbot Vascular), NeoChord (NeoChord), V-Chordal-Off Pump (Valtech), CARILLON (Cardiac Dimensions). Second column from top to bottom: GDS Accucinch (GDS), Mitralign Bident (Mitralign), Cardioband TF (Valtech), Millipede Ring (Millipede). Third column from top to bottom: Cardica Mitral Repair (Cardica), MISTRAL (Mitralix), V-Chordal-Transfemoral, Kardium MR (Kardium). Fourth column from top to bottom: PS3 (MVRx), MitraFlex (TransCardiac), ValCare MV Repair (ValCare), Mitra-Spacer-Transapical.

in 15 patients. The device is implanted through a minithoracotomy with placement of a silicone band around the atrioventricular groove. It is then inflated and adjusted at the height of the mitral annulus to achieve the optimal result.

\section{MITRAL VALVE IMPLANTATION}

Nitinol-based devices that are currently under development are the Endovalve (Micro Interventional Devices, Inc, Newtown, Pa) device, the former Lutter-Lozonschi, now Tendyne valve (Tendyne Holdings, Roseville, Mich), the CardiAQ (CardiAQ valve Technologies Inc, Irvine, Calif) device, the Edwards FORTIS (Edwards Lifesciences), the MitrAssist (MitrAssist Ltd., Misgav, Israel) device, and the Neovasc Tiara (Neovasc Inc, Richmond, Canada) (Figure 2).

The Endovalve is implanted via a right minithoracotomy and delivery of the catheter-based valve through the left atrium. A true percutaneous version is under development.
The Lutter-Lozonschi, now Tendyne valve is delivered via a transapical approach. It consists of an atrial fixation system, a tubular piece with a mounted tricuspid pericardial valve, and a ventricular apical fixation system. ${ }^{20}$

The Edwards FORTIS consists of a central valve body, paddles, and an atrial flange and is only available in $29 \mathrm{~mm}$. The valve is nitinol-based, self-expanding, and has 3 bovine pericardial leaflets. The paddles are supposed to capture the native leaflets and secure them between the Fortis valve body and the paddles. It is delivered transapically with a 42-Fr system. First implants showed very promising results. ${ }^{21}$

The MitrAssist valve works with fixation of the transapically delivered valve at the papillary muscles. First-in-human procedures have not yet been performed. The Neovasc Tiara consists of a nitinol-based, selfexpanding frame, bovine pericardium leaflets, and ventricular anchors to fix the valve onto the fibrous 


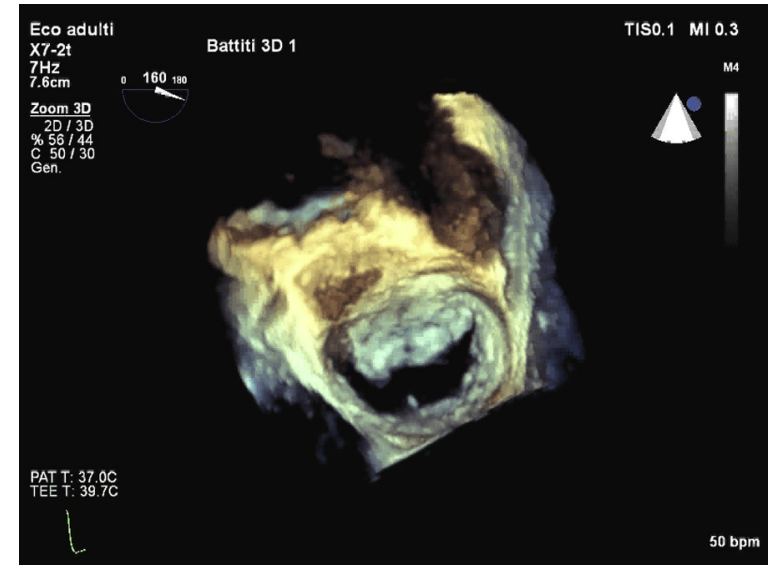

VIDEO 1. Three-dimensional echocardiogram showing a degenerated mitral valve with a chordal rupture on the scallop 2 of the posterior leaflet. Video available at http://www.jtcvsonline.org/article/S0022-5223(16) 30263-X/addons.

trigone and the posterior annulus. The valve is anatomically D-shaped. It is introduced by a 32-Fr sheathless system with a self-dilating tip via a transapical approach. First-in-human implants were successful without complications. A feasibility study with 30 patients is ongoing. ${ }^{22}$

The CardiAQ system is made for both transfemoral and transapical access. It is placed intra- and suprannular to preserve the LV contractility and maximize the left ventricular outflow tract (LVOT) area. The anchoring frame is designed for annular attachment without the use of radial force and preservation of chordate and leaflets. It consists of a bi-level, self-expanding nitinol frame. ${ }^{23}$ A CE mark trial with 100 patients is ongoing.



VIDEO 2. Three-dimensional echocardiogram showing the result after implantation of 2 MitraClips. Video available at http://www.jtcvsonline. org/article/S0022-5223(16)30263-X/addons.



VIDEO 3. Transesophageal echocardiography showing a case of ischemic mitral valve regurgitation with 2 separated jets. Video available at http:// www.jtcvsonline.org/article/S0022-5223(16)30263-X/addons.

\section{DISCUSSION}

Surgical MV repair is the reference treatment for patients with clinically significant MR. Low perioperative complication rates and excellent long-term outcomes can be achieved in centers with adequate expertise, especially in degenerative MR. Thus, although not fully clarified yet, surgery could be justified even in asymptomatic patients if repair is feasible. Of note, despite these premises, surgical MVR is denied to a large proportion of patients with significant grades of MR, especially those with functional mitral regurgitation, while at the same time, transcatheter therapies are making large steps forward. Of note, contrary to the aortic valve, the anatomy of the MV leads to a challenging and complex target regarding paravalvular leakage and LVOT obstruction. The eccentric geometry of



VIDEO 4. Transesophageal echocardiography showing the result after implantation of a single MitraClip. Video available at http://www.jtcvsonline. org/article/S0022-5223(16)30263-X/addons. 

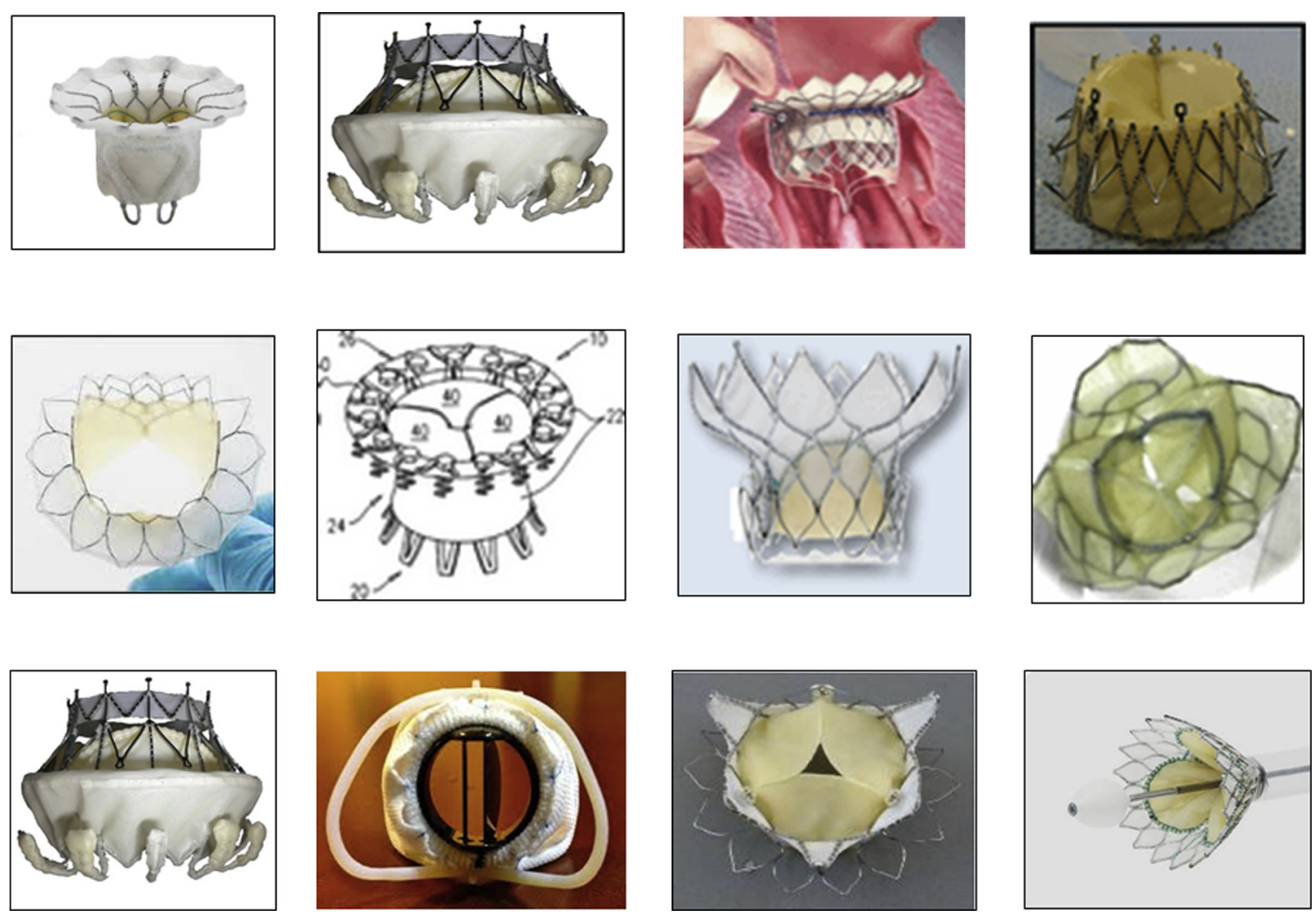

FIGURE 2. Transcatheter mitral valve implantation technologies. First column from top to bottom: FORTIS (Edwards Lifesciences), Tiara (Neovasc), TMVI-TA (CardiAQ). Second column from top to bottom: TMVI-TF (CardiAQ), Caisson TMVR (Caisson), MitraCath (Emory University). Third column from top to bottom: HighLife Mitral Valve Replacement (HighLife), Medtronic TMVR (Medtronic), MitrAssist Valve (MitrAssist). Fourth column from top to bottom: Navigate TMVR (NCSI), Tendyne/Lutter TMVR (Tendyne), Cardiovalve (Valtech).

the mitral orifice does not allow simple solutions for device delivery and anchoring.

To date, only the percutaneous edge-to-edge approach is applied on a large scale and the MitraClip has recently been incorporated into international guidelines; however, the field of transcatheter mitral valve implantation is evolving rapidly, and major anatomical challenges remain.

\section{MVR Versus Mitral Valve Implantation (MVI)}

Both MVR and MVI have several pros and cons. In patients with chronic MR, the dilation of the annulus requires large devices to achieve optimal fixation of the prosthesis and, thus, large delivery systems, at least greater than 30 Fr. Retrograde/transseptal approaches for MVI delivery may be challenging, given the angulation, the dimensions, and stiffness of the devices. A direct transatrial approach is a possible alternative, but it has been essentially abandoned because of suboptimal coaxial alignment. The transapical approach assures optimal coaxial alignment; however, the LV wall in patients with heart failure may be particularly fragile and arrhythmogenic. Dedicated closure devices could facilitate MVI. Finally, patients with severely depressed LV systolic function may not tolerate prolonged deployment time or rapid pacing.

Reliable fixation of the prosthesis is challenging, given the lack of heavy annular calcification in most patients. Moreover, fixation methods that rely on radial force are likely to fail as radial force poses the risk of compression of adjacent structures such as the LVOT, the conduction system, the coronary sinus, the left circumflex artery, and aortic root. Additional fixation elements are thus required.

MVR eliminates MR in a minority of the cases, and the degree of clinically meaningful MR reduction is still debatable, whereas the potential of MVI for complete and predictable abolition of MR is appealing. In patients with FMR, however, a mild degree of residual MR after repair may mitigate the acute increase in overload and serve to decompress the LV, making the procedure safer for those with severe LV dysfunction.

Because of the great anatomical variability of MR, physicians will likely need to develop expertise with more than 1 device and with advanced imaging; however, MVR will be tolerable and associated with fast recovery. MVR and MVI will probably be complementary and the future will conceivably be a tailored approach to both the valve and patient. 
In conclusion, the field of transcatheter MV therapy is quickly evolving; nevertheless, all current devices should be restricted to inoperable patients or to compassionate cases. Once clinical proof of safety and efficacy has been demonstrated, however, extension to a broader patient spectrum seems likely. Likewise in the field of transcatheter aortic valve replacement, an interdisciplinary heart team is mandatory.

\section{Conflict of Interest Statement}

Authors have nothing to disclose with regard to commercial support.

\section{References}

1. Nkomo VT, Gardin JM, Skelton TN, Gottdiener JS, Scott CG, EnriquezSarano M. Burden of valvular heart diseases: a population-based study. Lancet. 2006;368:1005-11

2. Mirabel M, Iung B, Baron G, Messika-Zeitoun D, Detaint D, Vanoverschelde JL, et al. What are the characteristics of patients with severe, symptomatic, mitral regurgitation who are denied surgery? Eur Heart J. 2007; 28:1358-65.

3. Lim DS, Reynolds MR, Feldman T, Kar S, Herrmann HC, Wang A, et al. Improved functional status and quality of life in prohibitive surgical risk patients with degenerative mitral regurgitation following transcatheter mitral valve repair with the MitraClip(R) system. J Am Coll Cardiol. 2014;64:182-92.

4. Descoutures F, Himbert D, Maisano F, Casselman F, de Weger A, Bodea O, et al. Transcatheter valve-in-ring implantation after failure of surgical mitral repair. Eur J Cardiothorac Surg. 2013;44:e8-15.

5. Alfieri O, Maisano F, De Bonis M, Stefano PL, Torracca L, Oppizzi M, et al. The double-orifice technique in mitral valve repair: a simple solution for complex problems. J Thorac Cardiovasc Surg. 2001;122:674-81.

6. Feldman T, Wasserman HS, Herrmann HC, Gray W, Block PC, Whitlow P, et al. Percutaneous mitral valve repair using the edge-to-edge technique: six-month results of the EVEREST Phase I Clinical Trial. J Am Coll Cardiol. 2005;46:2134-40.

7. Feldman T, Kar S, Rinaldi M, Fail P, Hermiller J, Smalling R, et al; EVEREST Investigators. Percutaneous mitral repair with the MitraClip system: safety and midterm durability in the initial EVEREST (Endovascular Valve Edge-to-Edge REpair Study) cohort. J Am Coll Cardiol. 2009;54:686-94.

8. Clinical outcomes assessment of the mitraclip percutaneous therapy (COAPT) clinical trial. Clinical trial: NCT01626079. Available at: http://clinicaltrials. gov/show/NCT01626079. Accessed April 2015.

9. A randomized study of the MitraClip device in heart failure patients with clinically significant functional mitral regurgitation (RESHAPE-HF). Clinical trial: NCT01772108. Available at: http://clinicaltrials.gov/show/NCT01772108. Accessed April 2015.

10. Schofer J, Siminiak T, Haude M, Herrman JP, Vainer J, Wu JC, et al. Percutaneous mitral annuloplasty for functional mitral regurgitation: results of the CARILLON Mitral Annuloplasty Device European Union Study Circulation. 2009;120:326-33.

11. Harnek J, Webb JG, Kuck KH, Tschope C, Vahanian A, Buller CE, et al. Transcatheter implantation of the MONARC coronary sinus device for mitral regurgitation: 1-year results from the EVOLUTION phase I study (Clinical Evaluation of the Edwards Lifesciences Percutaneous Mitral Annuloplasty System for the Treatment of Mitral Regurgitation). JACC Cardiovasc Interv. 2011;4:115-22.

12. Sorajja P, Nishimura RA, Thompson J, Zehr K. A novel method of percutaneous mitral valve repair for ischemic mitral regurgitation. JACC Cardiovasc Interv. 2008; 1:663-72.

13. Tops LF, Van de Veire NR, Schuijf JD, de Roos A, van der Wall EE, Schalij MJ et al. Noninvasive evaluation of coronary sinus anatomy and its relation to the mitral valve annulus: implications for percutaneous mitral annuloplasty Circulation. 2007;115:1426-32

14. Erglis A, Thomas M, Morice MC, Narbute I, Zabunova M, Hovasse T, et al. The Arto transcatheter mitral valve repair system. EuroIntervention. 2015;11(suppl W):W47-8.

15. Maisano F, Vanermen H, Seeburger J, Mack M, Falk V, Denti P, et al Direct access transcatheter mitral annuloplasty with a sutureless and adjustable device: preclinical experience. Eur J Cardiothorac Surg. 2012;42: 524-9.

16. Maisano F, Taramasso M, Nickenig G, Hammerstingl C, Vahanian A, MessikaZeitoun D, et al. Cardioband, a transcatheter surgical-like direct mitral valve annuloplasty system: early results of the feasibility trial. Eur Heart J. 2016;37: 817-25.

17. Mandinov L, Buellesfeld L, Kuck K-H, Grube E. Early insight into Mitralign direct annuloplasty for treatment of functional mitral regurgitation. Intervent Cardiol Rev. 2011;6:170-2

18. Goel R, Witzel T, Dickens D, Takeda PA, Heuser RR. The QuantumCor device for treating mitral regurgitation: an animal study. Catheter Cardiovasc Interv. 2009;74:43-8

19. Seeburger J, Rinaldi M, Nielsen SL, Salizzoni S, Lange R, Schoenburg M, et al. Off-pump transapical implantation of artificial neo-chordae to correct mitral regurgitation: the TACT Trial (Transapical Artificial Chordae Tendinae) proof of concept. J Am Coll Cardiol. 2014;63:914-9.

20. Lutter G, Lozonschi L, Ebner A, Gallo S, Marin y Kall C, Missov E, et al. First-in-human off-pump transcatheter mitral valve replacement. JACC Cardiovasc Interv. 2014; 7:1077-8

21. Bapat V, Buellesfeld L, Peterson MD, Hancock J, Reineke D, Buller C, et al Transcatheter mitral valve implantation (TMVI) using the Edwards FORTIS device. EuroIntervention. 2014;10(suppl U):U120-8.

22. Cheung A, Stub D, Moss R, Boone RH, Leipsic J, Verheye S, et al. Transcatheter mitral valve implantation with Tiara bioprosthesis. EuroIntervention. 2014; 10(suppl U):U115-9.

23. Swaans MJ, van der Heyden JAS. Mitral valve devices. In: Rajamannan NM, ed. Cardiac Valvular Medicine. London: Springer-Verlag; 2013:187-209.

Key Words: mitral regurgitation, transcatheter treatment, mitral valve implantation, mitral valve repair 